\title{
Diet and orthodontics- A review
}

\author{
Maymona Ali Ibraheem ${ }^{(1)}$, Mohammed Nahidh ${ }^{(2)}$ \\ https://doi.org/10.26477/jbcd.v33i3.2951
}

\begin{abstract}
During the course of fixed orthodontic therapy, patients should be instructed to eat specific food stuffs and beverages in order to maintain good health for the dentition and supporting structures, and prevent frequent attachment debonding that prolongs the treatment duration. After searching and collecting articles from 1930 till July 2021, the current review was prepared to emphasize various types of foods that should be taken during the course of fixed orthodontic therapy and to explain the effect of various food stuffs and beverages on the growth and development of craniofacial structures, tooth surfaces, root resorption, tooth movement, retention and stability after orthodontic treatment and the effect on the components of fixed orthodontic appliance.
\end{abstract}

Key words: Diet, nutrition, fixed orthodontics, health. (Received: 26/6/2021, Accepted: 26/7/2021)

\section{INTRODUCTION}

Individuals are more concerned and aware of maintaining healthy lifestyle and good health that necessitates a well-balanced diet. Generally, nutrition affects the development of many body's organs in addition to the sexual development's timing, so delay menarche is mostly seen with malnutrition, preponing it in the obesity ${ }^{(1)}$.

Dietary counseling and nutritional education associated with oral health have become one of the significant dental education components, with so much emphasis on more nutritional food choices and healthier foods. American Dental Association (2) reported the accreditation guidelines of dental schools "the graduate must be competent to provide dietary counseling and nutritional education relevant to oral health."

Lately, governments in various nations were working for formalizing systems of national nutrition monitoring, and there were new fat and salt labeling laws for foods ${ }^{(3)}$.

With the spotlight on nutritional issues, it seems like a good time to look at how the orthodontic treatments are affecting the diet of patients. Orthodontic treatment causes physiologic, physical, and emotional stress, which increases nutrient utilization and mobilization, thereby increasing an individual's nutritional needs. Because the nutritional requirements of adolescents (the age of a common orthodontic patient) were already strained by development and growth, the emotional stress of puberty, maintaining a well-balanced diet is critical ${ }^{(4)}$.

Orthodontists frequently advise their patients to eat soft foods throughout treatment for avoiding pressure sensitivity, yet some are providing specific diet charts or instructions, without

(1) General Dentist, Baghdad, Iraq.

(2) Assistant Professor. Department of Orthodontics, College of Dentistry, University of Baghdad.

Corresponding author: m_nahidh79@codental.uobaghdad.edu.iq them, patients often turn to easy-to-eat, convenient foods, paying little attention to the food's nutrient content ${ }^{(5)}$.

This review was prepared to highlight the types of foods that should be taken during the course of fixed orthodontic therapy and to explain the effect of various food stuffs and beverages on the growth and development of craniofacial structures, tooth surfaces, root resorption, tooth movement, retention and stability after orthodontic treatment and the effect on the components of fixed orthodontic appliance.

\section{REVIEW OF LITERATURES Diet and Nutrition}

The sum of food consumed by a person or other organism is called diet, while nutrition can be defined as "the science of food, nutrients and other substances. In addition to their interaction, action, and balance in relation to the health and diseases and the processes through which organisms ingest, absorb, digest, utilize, transport and excrete foods" (6).

\section{Classification of Foods}

Milward and Chapple ${ }^{(7)}$ divided food into two broad categories; macronutrients (fats, carbohydrates and proteins) which are required in large quantities from the diet, and micronutrients (minerals, vitamins, trace elements, and aminoacids) which are only required in small quantities in the diet and considered essential for a range of biological processes important in supporting optimal health.

In another classification, foods scientifically can be divided into 6 groups; each one of them presents some, yet not all, of the nutrient's humans require. Each group is equally important; no one can take the place of another. Humans require all of them for good health. A healthy diet consists of the following food groups ${ }^{(8)}$ : 


\section{Cereals (Carbohydrates)}

This group meets a fourth of total energy needs. Bread and rice are the most common cereal forms consumed in diet. Since the majority of grain products are easy to chew and soft, they are an easy food group for braces wearers.

\section{Milk and Milk Products}

Dairy products are comprised of approximately fourth of total dietary needs. A calcium-rich diet is essential for strong teeth and bones. Calcium, potassium, vitamin $\mathrm{D}$, and even protein are all found in dairy products. In addition, dairy products are considered as a great choice for braces wearers since they are soft and require little chewing. Milk, yogurt, milk shakes, and various cheese types are typical dairy products in diets, and patients must be encouraged to consume them.

\section{Fruits}

Fruits are important for healthy diet, yet they might be difficult to eat with braces. Due to the orthodontic brackets, hard fruits such as unripe pears, apples, and peaches might be difficult to bite into. Even the softest food might be a challenging following a wire change. Hard fruits might be cut into small bite sized pieces and chewed with the back teeth. In addition, fruit juice is a healthy and convenient option if nothing else works. With all that metal around the teeth, it is often difficult to chew or bite something extremely cold.

\section{Vegetables}

Vegetables make up approximately a fourth of total dietary requirements. Vegetables are high in minerals and vitamins, which are needed by growing bodies. Because the majority of vegetables are consumed cooked, they do not pose a significant problem for braces wearers. They might be meshed up more for added comfort. Salads or raw vegetables might be cut or grated into bite-sized pieces.

\section{Nuts and Seeds}

Choosing carefully from such vegetarian group will allow keeping the braces in place. Seeds and nuts are both small and hard, which can be difficult for people who wear braces.

\section{Meat}

Meat is difficult to chew for people who wear braces due to the fact that it is fibrous. It isbest not to eat meat straight from the bone. As a source of protein, cottage cheese or tofu are safe alternatives to meat. Before eating, orthodontic patients must choose tender, lean cuts of meat and cut them into bite-size pieces.

\section{Relation between Malocclusion, Malformation and Malnutrition}

The adequate development and growth of an individual is determined by the intake of required nutrition. Any nutrient deficiency throughout the formative stages of organs and tissues causes permanent and severe deformation. Also, nutrition affects the sexual development's timing, delay menarche in cases of malnutrition and preponing it in cases of obesity ${ }^{(1)}$.

There is a link between malnutrition and slow development and growth of the facial bones ${ }^{(9)}$. Proteins play a role in the growth of teeth and jaws in animals, with a considerable impact on the size and shape of mandible so as a result, malnutrition causes alterations in spatial arrangements that are related to teeth in jaws, both absolute and relative. Malnutrition can cause a decrease in jaw height, skull base length (10), lower facial height and maxilla-mandibular width (11). Other undesirable skeletal effects include enlargement of medullary spaces, cortical thinning, and decreased osteoclastic and osteoblastic activity ${ }^{(12)}$.

It has been suggested that the dietary deficiencies are considered as a cause of dentofacial deformities. Animals fed on diet low in zinc, riboflavin and folic acid might have cleft lip and palate in offspring ${ }^{(13)}$.

Nutritional deficiencies might change the functions related to the body's endocrine glands, affecting not just the whole body's development and growth, and also the dentition (14).

In a cross-sectional study, Jasim et al. (15) found that there were significant relations between nutritional status with crowding, facial height, and adverse oral habits. These might be modulated by other local factors like caries and bad oral habit sequel.

The effect of nutritional status on the occlusion of primary dentition had been evaluated by Abdul Wadood and Khalaf ${ }^{(16)}$ among Iraqi 5 years old children. This study failed to find out a relationship between the occlusal relation and malnutrition. On the other hand, Jabber and Diab (17) concluded that prenatal malnutrition had some effect on the occlusal relation among kindergarten children.

Minerals and vitamins are important parts of a balanced diet and play a significant role in the normal development and growth. Calcium, phosphorous and vitamin $\mathrm{D}$ are vital for the formation of teeth and bones. Deficiency of vitamin $\mathrm{D}$ results in retarded teeth, jaw and condyle development, rickets and maxillary dysplasia, and it makes it difficult to close facial 
sutures, resulting in an open bite, transverse hypodimension, and a misshapen palate ${ }^{(18)}$. A person with a magnesium deficiency may develop a bruxism habit ${ }^{(19)}$.

An excess of vitamin A during the critical growth period markedly inhibits the neural crest cell development and upsets the normal balance between bone formation and resorption ${ }^{(18)}$, while the deficiency of vitamin A combined with deficiency of protein results in insufficient bone growth and malocclusion of teeth ${ }^{(20)}$.

In comparison to subjects on a hard diet, subjects on a soft diet had narrow arches due to underdeveloped muscles and supporting structures ${ }^{(21)}$. Breastfeeding is essential for the synchronicity and development of orofacial muscles, which allows the maturation of different vital functions and the dentofacial structures' growth ${ }^{(22)}$. Altered growth of craniofacial bones led to insufficient space for teeth to erupt resulting in crowding, impactions and ectopic eruptions ${ }^{(23)}$.

\section{Effect of Orthodontic Treatment on Diet}

The effect of fixed orthodontic treatment on patients' weight and dietary intake are still requiring further investigations. Orthodontic treatment causes physical, physiological and emotional stresses which induce changes in the nutrition of patients. Orthodontic treatment may alter the consistency, quality and quantity of a person's diet. Patients having orthodontic treatment will need to have alteration in their food choices because of discomfort, sensitivity and pain on biting and chewing (24).

For the purpose of avoiding bracket debonding and appliance breakage throughout fixed orthodontic therapy, orthodontists advise patients to avoid gummy, sticky, chewy, or extremely hard foods. Throughout orthodontic treatments, a preference for soft foods leads to dietary changes that decrease carbohydrate and fiber intake while increasing fat intake. Manganese and copper levels were found to be lower with orthodontic treatments by Strause and Saltzmann ${ }^{(25)}$. It was linked to a lack of whole grains, nuts, and a reduction in vegetable and fruit consumption.

Copper is needed for the production of red blood cells and hemoglobin, as well as being a component of redox system enzymes and collagen cross-linking, in addition to normal pigmentation. Manganese is essential for bone remodeling as well as glucose metabolism ${ }^{(26)}$.

\section{Effects of the Diet on the Orthodontic Treatment}

The success of orthodontic treatment is heavily reliant on the oral tissues' health. The orthodontic treatment is hampered by inflamed oral tissues, frequent ulcerations, and compromised periodontal tissues. As a result, the quality of one's diet has a direct impact on the effectiveness of orthodontic treatment ${ }^{(27)}$.

\section{Effect on the Dental and Periodontal Structures}

\section{Demineralization and Dental Caries}

Decalcification of teeth under brackets and bands is caused by a high intake of carbonated soft drinks, uncontrolled consumption of sugar, and poor oral hygiene, and if left untreated, it can lead to carious lesion. In a four-week period, Glatz and Featherstone (28) found measurable demineralization, gingival to brackets and bands. The existence of elastics, arch wires, springs, and other attachments interferes with the patient's capability for keeping a few portions of the brackets and teeth clean, resulting in demineralization. White spot lesions can be seen as a result of this.

Various foods contain buffers, such as protein in meat and calcium in milk, that might absorb or neutralize acids. Topical fluoride prevents dental caries via converting hydroxylapatite crystals in enamel to fluorapatite, which is less acid soluble. Excess fluoride, on the other hand, must be avoided for preventing dental fluorosis, which is characterized through brownish, corroded teeth (27). With a high intake of acidic drinks or a large amount of lemon, enamel surface erosion might be anticipated ${ }^{(29)}$.

\section{Root Resorption}

One of the major iatrogenic problems related to orthodontic treatment is root resorption, both internal and external resorption are possible. The root resorption problem is a significant challenge in orthodontic treatment that is influenced by diet. As stated by Marshall et al. ${ }^{(30)}$, animal studies show that deficient diets result in more resorption than adequate diets. Following vitamin and calcium deficiency, dogs were more susceptible to resorption, according to a Beck and Harris' study (31).

Vitamin D balances phosphorus and calcium in the body, and a lack of it causes cement resorption (32). In moderate hypocalcaemia, Engstrom et al. (33) had hypothesized that an increase in alveolar bone turnover is the root resorption cause. 


\section{Periodontal Problems}

Plaque and calculus formation is aided by a soft diet, whereas fibrous and hard foods have both a surface cleansing effect that prevents plaque formation and a stimulatory effect that increases the density of the alveolar bone ${ }^{(34)}$.

Generally, nutritional deficiencies do not cause gingivitis or the formation of a periodontal pocket, but they can worsen the damaging impacts of the local irritants on periodontium ${ }^{(35)}$.

Vitamins are of high importance for maintaining periodontal healthy since the experimental animal studies showed that vitamin A deficiency may result in hyperkeratosis and hyperplasia of the gingiva with a tendency for increased periodontal pocket and healing retardation of the gingival wound ${ }^{(32)}$.

Gingivitis, angular chelitis, glossitis, and oral mucositis have all been linked to the deficiency of vitamin B. Non-inflammatory necrosis of the periodontal ligament, gingiva, and alveolar bone is a sign of folic acid deficiency. Scurvy is caused by a disruption in collagen metabolism, which affects repair potential and tissue regeneration $(32,36)$.

\section{Effects upon Tooth Movement and Orthodontic Correction Stability}

Orthodontic forces induce the biological responses, involving complicated combining osteoblastic with osteoclastic activities. The movement of the tooth requires the simultaneous synchronous collagen metabolism functioning. The lack in the normal synthesis of the collagen, due to a lack in the ascorbic acid, has led to a nearly full osteogenesis cessation and periodontal ligament disorganization. It seemed that the ascorbic acid is important for normal alveolar bone and periodontal ligament morphology ${ }^{(37)}$.

The metabolism of the collagen is dependent upon the adequate vitamin $\mathrm{C}$ supply for producing mature collagen. It was noticed as well in individuals who have vitamin $\mathrm{C}$ deficiency that the teeth that were orthodontically corrected have not been stable and relapse faster in comparison with individuals who are not vitamin $\mathrm{C}$ deficient because of the presence of a large resorption lacunae and an increase in the osteoclastic activities, that are secondary to the deficiency of vitamin $\mathrm{C}$, which has jeopardized the remodeling of the bone that slows the movement of the orthodontic tooth ${ }^{(38)}$. Moreover; Miresmaeili et al. ${ }^{(39)}$ found that oral administration of vitamin $\mathrm{C}$ for rats can enhance tooth movement with the formation of more osteoclast lacunae around the root in the pressure site.
It was stated that $17 \%$ to $72 \%$ of the orthodontic patients can have sub-optimal ascorbic acid levels and a deficiency could result in affecting the periodontal ligament's connective tissue and the osteoid formation. In addition, nutritional stress to the periodontium, coupled with the irritation of orthodontic bands and brackets may cause an altered gingival response thereby impacting the movement of the tooth as well as the retention that follows the orthodontic treatments ${ }^{(24,40,41)}$.

Dietary lipids contain two types of polyunsaturated fatty acids essential to the human body namely; the $n-6$ and $n-3$ series are derived from linoleic and alpha-linolenic acids, respectively. The n-6 fatty acids produced arachidonic acid, while dietary n-3 fatty acids have actions similar to those of Non-Steroidal Anti-Inflammatory Drugs (NSAIDs) by inhibiting the appearance of osteoclasts thus reducing the rate of tooth movement. So, intake of dietary lipids might affect bone remodeling and subsequently orthodontic tooth movement ${ }^{(42,43)}$.

Carbonated soft drinks have deleterious effect on tooth movement as they may alter bone metabolism and impact the process of the bone remodeling and successive orthodontic tooth movement ${ }^{(29)}$.

For the modest bone health, the ratio of Calcium phosphorous has to be $>1$ in the adolescent diet ${ }^{(44)}$. Vitamin D had proved to increase the rate of tooth movement in human beings after local administration in the periodontal ligament space ${ }^{(45)}$.

\section{Effect on Fixed Orthodontic Appliance Materials and Components}

\section{Effect on the Shear Bond Strength}

Many studies (both in-vivo and in-vitro) have been conducted to test the effect of different types of food simulants and carbonated soft drinks on the shear bond strength, adhesive remnant index and microleakage of orthodontic brackets. The results varied according to the experiments but the general findings indicated that soft carbonated drinks may have an impact on the shear bond strength in two ways; first, through the deterioration of the adhesive material structure, and second, through leading to erosive lesions on the surface of the enamel that surrounds the brackets, with the main beverage composition effect and the overall acid content, instead of the beverage $\mathrm{pH}$, which determines actual aggression towards enamel ${ }^{(46-49)}$. 
2. Impacts upon the Chemical Characteristics, Surface Topography and Corrosion Resistance

Generally, food simulants and carbonated soft drinks play a role in the alteration of the chemical compositions and surface topography of different metal orthodontic brackets and archwires. These can be detected by releasing of different ions, developing surface roughness and changed morphology due to the aggressiveness of these stuffs in destructing the protective oxide layer on these materials ${ }^{(50,51)}$.

3. Effects upon the Color Stability of Clear Retainers, Elastics and Esthetic Brackets

There is general agreement about developing discoloration of clear retainers, esthetic brackets and clear elastics by different food and beverages stuffs. This was confirmed by various in-vivo and in-vitro studies ${ }^{(52-55)}$.

\section{Effects on Elastics' Force Decay}

The findings of different studies suggested a controversial impact of carbonated soft drinks on the force decay of various types of elastics. This may be related to the type, method and configuration of the manufacturing in addition to the $\mathrm{pH}$, content, and temperature of carbonated soft drinks ${ }^{(56-59)}$.

\section{Balanced Diet and Orthodontic Treatment}

Throughout the orthodontic treatment, the nutritional history has to be considered and the diet of the patient must be adjusted for including all of the important elements, keeping under consideration of the patient's convenience, habits, preferences and dislikes. The dairy products (such as milk, ice cream and cheese) have to be prescribed throughout the orthodontic treatment, due to the fact that they are soft and helpful for the remodeling of the bones throughout the movement of the tooth ${ }^{(60)}$.

Khatri and Kolhe ${ }^{(61)}$ stated that throughout the orthodontic treatments, the patients are asked to follow a pattern of stop, halt and go in the food consumption; some of them are simply presented in Figure 1:

\section{Stop (Never Eat)}

Chewing gums, toffees, caramel, nan and boiled candy, pop-corn kernels, ice cubes, corn, raw apple or carrots, pizza crust, hard pretzels, nuts, chocolate chips, carbonated soft drinks, dry fruits, Guava, meat with bone, halwa, ice cream with nuts, and sticky snacks.

\section{Halt (Think before Eating)}

Nacho chips, Bagel, raw vegetables, ribs, chicken wings, loose corns, hard fruit cut to smaller pieces, fruit with pits, high sugar foods and crusty bread.

\section{Go (Can Eat)}

French fries, potato chips, steamed vegetables, sausage, yoghurt, soup, jelly, cheese, cereal in milk, milk shakes, eggs, banana, ice cream with no nuts, cake, Biriyani, pasta potatoes, pudding, caramel bars, peanut butter cups, orange, boneless meat, burger, fish, puri bread.

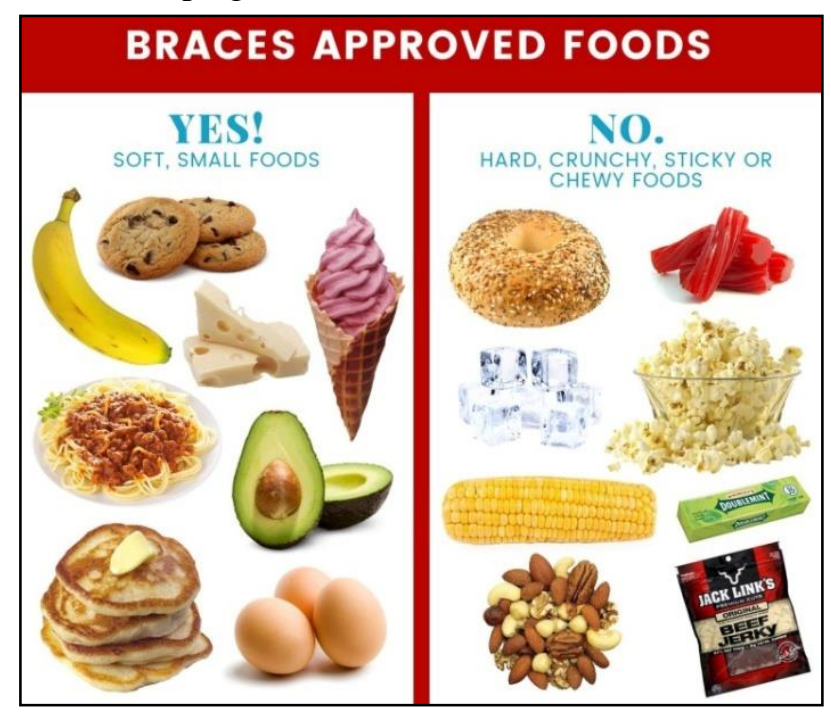

Figure 1: Allowed and not allowed foods in the course of fixed orthodontic therapy ${ }^{(62)}$ 


\section{Dietary Considerations in Orthognathic Surgery Patients}

Before and after jaw surgery, it is important to eat well as healing requires good nutrition. The mouth represents entry portal of the foods to the body, which is why, maxillofacial surgery of those structures could lead to the impairment of the food intake before, as well as after the surgery and so sufficient nutritional support has to be ensured for those patients. After surgery, it is often best to take smaller meals or snacks more frequently rather than relying on the typical three meals per day ${ }^{(63)}$.

Patients need a source of energy as well as a source of protein. The proteins, carbohydrates, and fatty acids are energy sources. Glucose is a source of energy for vital organs like brain. However, hyperglycemia is not desirable. Fatty acids produce more energy and certain essential fatty acids must be supplied by the diet. Protein is also important for cellular proliferation and imparting strength to the fracture repair. If it is absent then the wound healing is delayed ${ }^{(4)}$.

Vitamin A helps in epithelization, synthesis of the collagen and the cross linking and differentiation of the fibroblasts. Vitamin C deficiency leads to impairment in the collagen synthesis and wound healing. Calcium and vitamin $\mathrm{D}$ help in healing the hard tissues. Vitamin $\mathrm{E}$ acts as an antioxidant and thus reduces the damage from the free oxygen radicals. Large vitamin $\mathrm{E}$ doses inhibit the healing as well. Vitamin $\mathrm{K}$ helps activate various factors of clotting and thus is essential for blood clot formation during healing ${ }^{(43)}$.

Initially after surgery, patients should eat and drink using a small spoon, plastic syringe or straw $(36,64)$.

Just like in normal orthodontic patients, orthognathic patients have a list of allowed and non-allowed food stuffs as followed ${ }^{(4,63)}$ :

\section{Foods preferred}

- Puree/liquidized diet

- Use milk, fruit juice, sauces, gracy, soup etc.

- Meat, poultry, fish and alternatives should be liquidized with savory Saur

- Carbohydrates-mash potato with milk and butter

- Fruit and vegetables can be liquidized

\section{Foods to avoid}

- Stringy foods such as green beans and celery

- Crunchy food such as muesli, crisps, toasts, nuts and crispy bread

- Foods with skins or husk such as sausages, peas etc.
- Chewy food such as tough meat and toffees

Dietary Allergy

Dietary substances might act as allergens leading to sensitize the human immune system resulting in hypersensitivity reaction. Such allergies can produce allergic rhinitis leading to oral breathing, which subsequently can affect the growth and development of both dental arches and the underlying skeletal bases often irreversibly causing what is called long face syndrome. The most common allergens included; cow milk, used in processed infant foods, wheat and wheat products, fish and eggs ${ }^{(42)}$.

\section{CONCLUSIONS}

The following conclusions have been drawn from this review:

1. For the purpose of maintaining a healthy body, there is a high significant value in following a balanced diet that includes of all of the fundamental nutrients required by the body and also meets the individual's calorie requirements, with their age, activity level and gender under consideration.

2. For the optimization of the physiological responses of the patient to the orthodontic treatments, it can be useful providing the dietary guidance to the patient by obtaining the history of the nutrition, evaluation of the diet, instructing patients about the components of the diet that are important for the oral health, motivating them to enhance the diet and follow up for supporting the patient's efforts in changing the food behaviors.

3. Orthodontists usually instruct the patients to eat soft foods throughout the treatment for the purpose of accommodating the pressure sensitivity that is encountered with the movement of the tooth.

4. Patient who have braces, preferring or switching over to the convenience foods like the pastries, cakes, cookies and ice creams that have high amount of the fats and simple sugars have to be educated about the value of the vegetables, fruits, cereals and grains in their daily nutrition.

5. The compliance with the dietary advices is more possible in the case where the followup has been provided. The dietary progress has to be discussed at further appointments. The nutrition care has to be one of the integral parts of the orthodontic care.

6. The effect of some food stuffs and beverages on the general health, bone, teeth and orthodontic materials used inside the oral cavity like brackets, arch wires, elastics, and 
springs should be discussed with the orthodontic patients before commencing the treatment with fixed orthodontic appliance.

7. Pregnant women should be advised to take supplementary vitamins and minerals to ensure proper development of fetus organs. After delivery, breast-feeding is the best type of feeding during that period for providing the useful components in mother milk and aiding in well-developed dental arches.

\section{REFERENCES}

1. Epstein LH, Wing RR, Valoski A. Childhood obesity. Pediatr Clin North Am 1985; 32(2): $363-$ 379.

2. American Dental Association. Procedures for evaluation requirements and guidelines for dental education programs. Chicago: American Dental Association, 1987.

3. Yetley EA, Beloian AM, Lewis CJ. Dietary methodologies for food and nutrition monitoring. Vital Health Stat 4 1992; 27: 58-67.

4. Maheshwari S, Tariq M, Gaur A, et al. A systematic nutritional and dietary guideline for orthodontic and orthognathic surgery patients. Indian $\mathrm{J}$ Orthod Dentofacial Res 2017; 3(3): 136-140.

5. Mehta V, Bagga MK, Bhatti BK. How diet affects an orthodontic treatment outcome- A Review. Inter J Res Review 2018; 5(5): 46-51.

6. Council on foods and nutrition. Nutrition teaching in medical schools. J Am Med Assoc 1963; 183(11): 995-997.

7. Milward MR, Chapple IL. The role of diet in periodontal disease. Clin Dent Health 2013; 52(1): 18-21.

8. Ashish A, Pradeep R, Utkarsh S, et al. Diet and nutrition: conceptual importance in the specialty of orthodontics- a review. Int J Adv Res 2017; 5(6): 2198-2202.

9. Caceda J. Nutritional status and dental and skeletal development in Peruvian children. Proceedings of the $74^{\text {th }}$ General Session of the International Association for Dental Research, San Francisco, CA, USA; 1996.

10. Weissman S. Craniofacial growth and development in nutritionally compromised Peruvian children. Proceedings of the $71^{\text {st }}$ General Session of the International Association for Dental Research, Chicago, IL, USA; 1993.

11. Songvasin C. Early mal-nutrition and craniofacial growth. Proceedings of the $72^{\text {nd }}$ General Session of the International Association for Dental Research, Seattle, WA, USA; 1994.

12. Bourrin S, Toromanoff A, Ammann P, et al. Dietary protein deficiency induces osteoporosis in aged male rats. J Bone Miner Res 2000; 15(8): 1555-1563.

13. Munger RG. Maternal nutrition and oral clefts. In: Wyszynski DF (ed). Cleft lip and palate: from origin to treatment. Oxford University Press, New York; 2002.

14. Gupta S, Kirtaniya BC, Gupta KK, et al. Delayed teeth eruption A mirror to systemic deficiency of Vitamin D. Indian J Dent Sci 2015;7(1): 56-59.
15. Jasim ES, Garma NMH, Nahidh M. The association between malocclusion and nutritional status among 9-11 years old children. Iraqi Orthod J 2016; 12(1): 13-19.

16. Abdul Wadood MO, Khalaf MS. The effect of nutritional status on the occlusion of primary dentition among Iraqi preschool children. Inter $\mathbf{J}$ Med Res Health Sci 2019; 8(1): 10-14

17. Jabber WM, Diab BS. The impact of prenatal nutritional status on occlusion of primary teeth among kindergarten children in Al- Kut City/ Wassit. Indian J Forensic Med Toxicol 2020; 14(1): 593-597.

18. Zambrano M, Nikitakis NG, Sanchez-Quevedo MC, et al. Oral and dental manifestations of vitamin Ddependent rickets type I: report of a pediatric case. Oral Surg Oral Med Oral Pathol Oral Radiol Endod 2003; 95(6): 705-709.

19. Basiç V, Mehuliç K. Bruxism: An unsolved problem in dental medicine. Acta Stomat Croat 2004; 38(1): 93-96.

20. Ackermans MM, Zhou H, Carels CE, et al. Vitamin A and clefting: putative biological mechanisms. Nutr Rev 2011; 69(10): 613-624.

21. Beecher RM, Corrucini RS. Effects of dietary consistency on craniofacial and occlusal development in the rat. Angle Orthod 1981; 51(1): 61-69.

22. Feştilă D, Ghergie M, Muntean A, et al. Suckling and non-nutritive sucking habit: what should we know? Clujul Med 2014; 87(1): 11-4.

23. Anand K, Meka K, Maloth S, et al. Analyzing the role of malnourishment in malocclusion: A cross sectional study. J Pharm Bioallied Sci 2021; 13(5): 452-455.

24. Hickory W, Nanda R. Nutritional considerations in orthodontics. Dent Clin North Am 1981; 25(1): 195201.

25. Strause L, Saltman P. Role of manganese in bone metabolism. In: Kies C (ed). Nutritional bioavailability of manganese. American Chemical Society, Washington (DC); 1987.

26. Townsend CE. Nutrition and diet therapy. New York: Delmar publishers Inc; 1989.

27. Singh N, Tripathi $T$, Rai $P$, et al. Nutrition and orthodontics-interdependence and interrelationship. Res Rev: J Dent Sci 2017; 5(3): 18-22.

28. Glatz EGM, Featherstone JDB. Demineralization related to orthodontic bands and brackets-a clinical study. Am J Orthod 1985; 87(1): 87.

29. Abd Al-Hussain ZA, Nahidh M. Carbonated soft drinks and orthodontics: Review of literature. Turk J Orthod 2021; 34(2): 136-142.

30. Marshall JA. Root absorption of permanent teeth. II. A study of bone and tooth changes incident to experimental tooth movement. J Am Dent Assoc 1930; 17(7): 1221-1235.

31. Beck BW, Harris EF. Apical root resorption in orthodontically treated subjects: analysis of edgewise and light wire mechanics. Am J Orthod Dentofacial Orthop 1994; 105(4): 350-361.

32. Pavithra RS, Ramaprabha G, Rajasekar S, et al. Vitamin deficiency and periodontal disease- A tie-in relationship. Sch J App Med Sci 2017; 5(1A): 74-81.

33. Engström C, Granström G, Thilander B. Effect of orthodontic force on periodontal tissue metabolism. A histologic and biochemical study in normal and 
hypocalcemic young rats. Am J Orthod Dentofacial Orthop 1988; 93(6): 486-495.

34. Petti S, Simonetti R, Simonetti D'Arca A. The effect of milk and sucrose consumption on caries in 6-to11-year-old Italian school children. Eur J Epidemiol 1997; 13(6): 659-664.

35. Moynihan P, Petersen PE. Diet, nutrition and the prevention of dental diseases. Public Health Nutr 2004; 7(1A): 201-226.

36. Bose M, Bagga DK, Agrawal P. Managing nutrition but not damaging the orthodontic attachments: A consideration. Annals R.S.C.B. 2021; 25(4): 586590.

37. Litton SF. Orthodontic tooth movement during an ascorbic acid deficiency. Am J Orthod 1974; 65(3): 290-302.

38. McCanlies JM, Alexander CM, Rohneth JH, et al. Effect of vitamin $\mathrm{C}$ in the mobility and stability $\mathrm{OG}$ guinea pig incisor under the influence of orthodontic force. Angle Orthod 1961; 31(4): 257-263.

39. Miresmaeili A, Mollaei N, Azar R, et al. Effect of dietary Vitamin $\mathrm{C}$ on orthodontic tooth movement in rats. J Dentistry, Tehran Univ Med Sci 2015; 12(6): 409-413.

40. Boyera N, Galey I, Bernard BA. Effect of vitamin C and its derivatives on collagen synthesis and crosslinking by normal human fibroblasts. Int $\mathrm{J}$ Cosmet Sci 1998; 20(3): 151-158.

41. Lomanto ML. Stability in orthodontics and their relation with myofunctional orthodontics and vitamin C. SVOA Dentistry 2021; 2(3): 115-118.

42. Prabhakar R, Vikram NR, Saravanan R, et al. Nutrition and its imbalance and effects on developing oral tissues. Inter J Pharma Chem Sci 2013; 2(4): 1828- 1831.

43. Paria P, Patel R, Mehta F. Role of nutrition and hormone in orthodontics. J Emerging Technol Innovative Res 2020; 7(10): 2321-2325.

44. Riordan DJ. Effects of orthodontic treatment on nutrient intake. Am J Orthod Dentofacial Orthop 1997; 111(5): 554-561.

45. Al-Hasani NR, Al-Bustani AI, Ghareeb MM, et al. Clinical efficacy of locally injected calcitriol in orthodontic tooth movement. Inter $\mathrm{J}$ Pharm Pharmaceutical Sci 2011; 3(Supp 5): 139-143.

46. Oncag G, Tuncer AV, Tosun YS. Acidic soft drinks effects on the shear bond strength of orthodontic brackets and a scanning electron microscopy evaluation of the enamel. Angle Orthod 2005; 75(2): 247-253.

47. Al-Huwaizi AF, Yousif HAA. The effect of food simulants on the bond strength of orthodontic adhesive (An in vitro study). Iraqi Orthod J 2008; 4(1): $1-7$.

48. Navarro R, Vicente A, Ortiz AJ, et al. The effects of two soft drinks on bond strength, bracket microleakage, and adhesive remnant on intact and sealed enamel. Eur J Orthod 2011; 33(1): 60-65.
49. Nahidh M. The effects of various beverages on the shear bond strength of light-cured orthodontic composite (An in vitro comparative study). J Bagh Coll Dentistry 2014; 26(3): 144-148.

50. Hussien AH, Al-Mulla AA. The effect of food simulants on corrosion of simulated fixed orthodontic appliance. J Bagh Coll Dentistry 2010; 22(1): 68-75.

51. Mikulewicz M, Wołowiec P, Loster BW, et al. Do soft drinks affect metal ions release from orthodontic appliances? J Trace Elem Med Biol 2015; 31: 74-77.

52. Al-Huwaizi AF, Kalhan HF. Stainability of clear overlay retainers after immersion in different drinks. Iraqi Orthod J 2007; 3(1): 1-7.

53. Albo Hassan AF, Ghaib NH. Effect of different staining materials on color stability of sapphire brackets bonded with different types of light cure orthodontic adhesives (An in vitro study). J Bagh Coll Dentistry 2015; 27(2): 136-141.

54. Noori ZT, Ghaib NH. Color stability of different aesthetic archwires (An In vitro study). J Bagh Coll Dentistry 2016; 28(1): 164-168.

55. Mohammed SK. Assessment of the color stability of clear elastomeric ligatures (An in vivo study). A master thesis. Department of Orthodontics, College of Dentistry, University of Baghdad, 2017.

56. Yuwana CP, Christnawati C, Farmasyanti C. The effect of immersion time in three kinds of carbonated beverages on orthodontic elastic latex's tensile strength (In-Vitro). UIP Health Med 2016; 1(1): 63-67.

57. Barretto P, Souza G, Ferraz C, et al. Experimental evaluation of strength degradation of orthodontic chain elastics immersed in Cola beverage. Acta Scientific Dent Sci 2018; 2(5): 35-39.

58. Suprayugo M, Eriwati YK, Santosa AS. Effect of $\mathrm{pH}$ of soft drinks on force decay in orthodontic power chains. J Physics: Conference Series 2018; 1073(1): 1-6.

59. Sallam SM, Ramadan AA, Elgamy WE. Effect of some carbonated drinks on force decay of elastomeric chains: An in vitro study. Egyp Orthod J 2018; 53(1): 31-38.

60. Sharma R, Mittal S, Singla A, et al. Nutritional guidelines for orthodontic patients. Internet J Nutr Wellness 2009; 10(2): 1-4.

61. Khatri JM, Kolhe VD. Nutrition and orthodontics. Int J Orthod Rehabil 2018; 9(4): 163-167.

62. https://twitter.com/appleorthoch/status/84531200726 8171776, 2017.

63. Osak M. Nutrition and wound healing. Plast Surg Nurs 1993; 13(1): 29-36.

64. Brantley T, Kalamchi S. Nutrition support for osteotomy patients. In: Harris M, Hunt N (eds.). Fundamentals of orthognathic surgery and nonsurgical facial esthetics. $3^{\text {rd }}$ ed. Singapore: World scientific publishing Co.; 2018. 


$$
\text { المستخلص فلاص }
$$

خلال فترة علاج تقويم الأسنان الثابت ، يجب توجيه المرضى لتناول أطعمة ومشروبات معينة من أجل الحفاظ على صحة جيدة

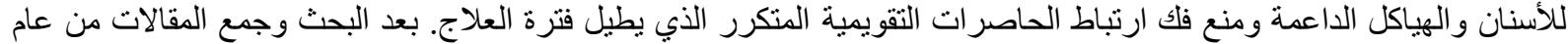

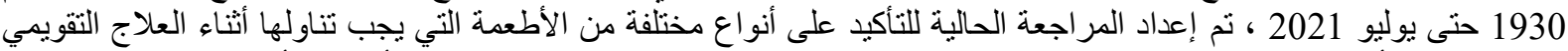

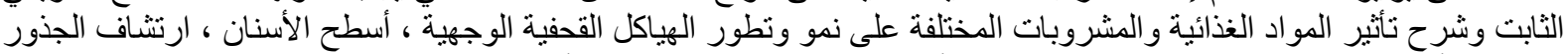

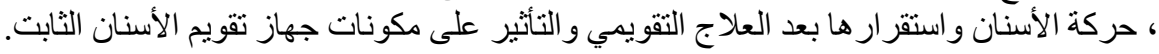

\section{(a) (1)}

Articles Published by Journal of Baghdad College of Dentistry is licensed under a Creative Commons Attribution 4.0 International License. 